\title{
Depression and Anxiety in Ovarian Cancer
}

\author{
Alpaslan Kaban* and Bulent Tekin \\ Department of Gynecology and Obstetrics, Istanbul University, Turkey \\ Department of Gynecology and Obstetrics, Medical Park Hospital, Turkey
}

Submission: April 22, 2017; Published: May 23, 2017

*Corresponding author: Alpaslan Kaban, Department of Gynecology and Obstetrics, Istanbul University, Turkey, Email: alpaslankaban@gmail.com

\begin{abstract}
Patients with ovarian cancer have a poor prognosis and often undergo aggressive surgery and chemotherapy. In the long-term and exhausting treatment of the disease, unfortunately, the psychological distress of these patients can be overlooked. These patients may be prone to psychological disturbances such as sleep disturbance, pain, fatigue, anxiety and depression in their disease process. The purpose of this review is to draw attention to the psychological changes experienced by patients with ovarian cancer.
\end{abstract}

Keywords: Psychological changes; Gynecological cancer; Psychological distress

\section{Introduction}

Ovarian cancer is the most deadly gynecological cancer among the other gynecological cancer such as endometrial, cervical or vulvar cancer [1]. More than half of the patients with ovarian cancer die within five years after diagnosis. The life time risk of developing ovarian cancer is approximately $1 / 70$, or $1.5 \%$ [1]. With an ageing population, the number of patients with ovarian cancer is increasing year on year [2].

When cancer is diagnosed in any woman, it is natural that the psychological condition is affected negatively. Moreover, patients in active treatment models of ovarian cancer have a high symptom burden. In fact, surgery, chemotherapy, and radiation contribute to symptoms that are more serius than the disease itself [3]. Psychological condition of the cancer patients is important, but the importance is neglected because of the aggressive treatment processes and the struggle to keep the patient alive. This issue is a relatively neglected area of research.

The purpose of this article, to draw attention to the psychological changes that these patients experience. We reviewed the studies which about psychological changes in patients with ovarian cancer in literature.

\section{Depression and Anxiety}

Depression and anxiety are psychiatric disorders that seriously affect the quality of life. The prevalence rates of anxiety and depression reported $14 \%$ - 56\% in patients with cancer $[4,5]$. The evaluation and management of psychological distress in patients with ovarian cancer is not well reported [6].

In a prospective cohort study, Price et al. [7] evaluated 798 women with ovarian cancer and founded clinical depression rates were $5.9 \%$ and reported that depression is significantly more common in women with ovarian cancer than in the general population.

In a study evaluating psychological distress and quality of life in patients with ovarian cancer, Bodurka et al. [8] Reported depression and anxiety rates were $21 \%$ and $29 \%$.

Norton et al reported in their study that psychological distress rate was 50\% among women with ovarian cancer [9].

In a meta analysis, Watts et al evaluated 3623 patients with ovarian cancer and reported that the prevalence of depression and anxiety in women with ovarian cancer was significantly greater than in the healthy female population [10]. The rate of depression was highest in the pre-treatment period and decreased in post-treatment according to their meta analysis. Authors founded the depression prevalence rates were 25\%, $22 \%$, and $12 \%$ in identified pretreatment, on-treatment and post-treatment periods. However, pretreatment, on-treatment and post-treatment anxiety pre valences were founded 19\%, $26 \%$ and $27 \%$. Accordingtothe meta-analysis; despite the depression rate decrease anxiety is increasing over time.

Hipkins et al. [11] evaluated levels of anxiety and depression in patients with ovarian cancer during the 3 month period following the end of chemotherapy treatment. At the completion of chemotherapy, they founded the anxiety rate was $38 \%$ and depression rate was 33\%. At 3 months follow-up, rates were $19 \%$ and $47 \%$ for depression and anxiety. It seems a significant reduction in cases of depression but an increase in cases of anxiety in post-treatment period in the study in the study as 
well as in meta analysis of Watts et al. Ina systematic review, Arden- Close et al reported that the rewash strong evidence for a relationship between younger age, being diagnosed with more advanced disease, more physical symptoms and shorter time since diagnosis with increased levels of anxiety and/or depression [6].

There are interesting findings about the relationship between immune system and psychological condition in patients with ovarian cancer. Costanzo et al. [12] founded in their study that poorer health-related quality of life was associated with higher levels of interleukin- 6 in peripheral blood among women with ovarian cancer. Authors asserted interleukin- 6 may be an independent marker of health-related quality of life among ovarian cancer patients.

Elevated interleukin-6 serum levels correlate with a poorprognosis in patients with ovarian cancer [13]. Similarly, Lutgendorf et al. [14] demonstrated significant relationships between interleukin-6, cortisol, and depression.

Depression or other psychological distress can affect the treatment processor survival of cancer disease negatively. Freyer et al. [15] in their study demonstrated symptoms of depression was independent prognostic factor for severe chemotherapy toxicity in elderly patients ( $>70$ years) with ovarian carcinoma. Likewise, depression was poor prognostic factors for overall survival in these patients.

\section{Sleep Disturbance}

Sleep disturbance is common and persistent in women with ovarian cancer $[16,17]$. Clevenger et al published that prior to surgery, $70.7 \%$ of patients with ovarian cancer reported sleep quality disturbance [16]. Australian Ovarian Cancer Study Group published $27 \%$ of 772 women with ovarian cancer reported sub-clinical symptoms of insomnia and $17 \%$ reported clinically significant insomnia.

\section{Pain and Fatigue}

About ninety percent of cancer patients suffer pain and fatique in the course of their illness [18]. Fatigue is common particularly during treatment [19]. Almost all patients with cancer are affected by fatigue and pain as factors affecting quality of life.

\section{Conclusion}

Patients with ovarian cancer be exposed to intensive treatment proceeds and have more psychological distress such as sleep disturbance, pain, fatigue, anxiety, or depression than the general population. Especially in the early stages of cancer diagnosis, the risk of depression that can disrupt the treatment plan and adversely affect survival should be considered.

\section{References}

1. Siegel RL, Miller KD, Jemal A (2016) Cancer statistics, 2016. CA Cancer J Clin 66(1): 7-30.
2. Møller H, Fairley L, Coupland V, Okello C, Green M, Forman D, et al. (2007) The future burden of cancer in England: incidence and numbers of new patients in 2020. Br J Cancer 96(9): 1484-1448.

3. Ferrell B, Smith S, Cullinane C, Melancon C (2003) Symptom concerns of women with ovarian cancer. J Pain Symptom Manage 25(6): 528538.

4. Mitchell AJ, Ferguson DW, Gill J, Paul J, Symonds P (2013) Depression and anxiety in long-term cancer survivors compared with spouses and healthy controls: A systematic review and meta-analysis. Lancet Oncol 14(8): 721-732.

5. Massie MJ (2004) Prevalence of depression in patients with cancer. J Natl Cancer Inst Monogr 32: 57-71.

6. Arden-Close E, Gidron Y, Moss-Morris R (2008) Psychological distress and its correlates in ovarian cancer: A systematic review. PsychoOncology 17(11): 1061-1072.

7. Price MA, Butow PN, Costa DSJ, King MT, Aldridge LJ, et al. (2010) Prevalence and predictors of anxiety and depression in women with invasive ovarian cancer and their caregivers. Med J Aust 193(5 Suppl): S52-S57.

8. Bodurka-Bevers D, Basen-engquist K, Carmack CL, Fitzgerald MA, Wolf JK, et al. (2000) Depression, anxiety, and quality of life in patients with epithelial ovarian cancer. Gynecol Oncol 78(3 Pt 1): 302-308.

9. Norton TR, Manne SL, Rubin S, Carlson J, Hernandez E, et al. (2004) Prevalence and predictors of psychological distress among women with ovarian cancer. J Clin Oncol 22(5): 919-926.

10. Watts S, Prescott P, Mason J, McLeod N, Lewith G (2015) Depression and anxiety in ovarian cancer: a systematic review and meta-analysis of prevalence rates. BMJ Open 5(11): e007618.

11. Hipkins J, Whitworth M, Tarrier N, Jayson G (2004) Social support, anxiety and depression after chemotherapy for ovarian cancer: a prospective study. Br J Health Psychol 9(Pt 4): 569-581.

12. Costanzo ES, Lutgendorf SK, Sood AK, Anderson B, Sorosky J, et al (2005) Psychosocial factors and interleukin-6 among women with advanced ovarian cancer. Cancer 104(2): 305-313.

13. Scambia G, Testa U, Benedetti Panici P, Foti E, Martucci R, et al. (1995) Prognostic significance of interleukin 6 serum levels in patients with ovarian cancer. Br J Cancer 71(2): 354-356.

14. Lutgendorf SK, Weinrib AZ, Penedo F, Russell D, DeGeest K, et al. (2008) Interleukin-6, cortisol, and depressive symptoms in ovarian cancer patients. J Clin Oncol 26(29): 4820-4827.

15. Freyer G, Geay JF, Touzet S, Provencal J, Weber B, et al. (2005) Comprehensive geriatric assessment predicts tolerance to chemotherapy and survival in elderly patients with advanced ovarian carcinoma: A GINECO study. Ann Oncol 16(11): 1795-1800.

16. Clevenger L, Schrepf A, Degeest K, Bender D, Goodheart M, et al. (2013) Sleep disturbance, distress, and quality of life in ovarian cancer patients during the first year after diagnosis. Cancer 119(17): 3234-3241.

17. Anderson KO, Getto CJ, Mendoza TR, Palmer SN, Wang XS, et al. (2003) Fatigue and sleep disturbance in patients with cancer, patients with clinical depression, and community-dwelling adults. J Pain Symptom Manag 25(4): 307-318.

18. Natcher WH (2002) NIH State-of-the-Science Statement on symptom management in cancer: pain, depression, and fatigue. NIH Consens State Sci Statements 19: 1-29.

19. Lawrence DP, Kupelnick B, Miller K, Devine D, Lau J (2004) Evidence report on the occurrence, assessment, and treatment of fatigue in cancer patients. J Natl Cancer Inst Monographs (32): 40-50. 
This work is licensed under Creative Commons Attribution 4.0 Licens

DOI: 10.19080/JGWH.2017.04.555647
Your next submission with Juniper Publishers will reach you the below assets

- Quality Editorial service

- Swift Peer Review

- Reprints availability

- E-prints Service

- Manuscript Podcast for convenient understanding

- Global attainment for your research

- Manuscript accessibility in different formats

( Pdf, E-pub, Full Text, Audio)

- Unceasing customer service

Track the below URL for one-step submission https://juniperpublishers.com/online-submission.php 